\title{
REPENSANDO AS FRONTEIRAS: A TRADUÇÃO DE IDENTIDADES NA OBRA DE JORGE LUIS BORGES
}

\author{
Denise Vallerius de Oliveira*
}

RESUMO: The rearrangement of concepts about frontiers has made possible the emergence of a different approach to Jorge Luis Borges' regionalist production - this production has often been misunderstood and supposedly considered inappropriate in relation to his other universal and remarkable masterpieces. However, the theme frontiers is set up within the limits of his pampa ${ }^{i}$ revealing the need to search for identities that insist on denying their own proper definition. It demands different representations: first, the frontier between the country and the city, in the shade of Sarmiento and Hernández - the former, desiring a civilized and urbane Argentinean identity, totally against the country barbarian; the latter, speaking of the pampa and the gaúchii as if in a free existence, opposite to the urbanized world. After these descriptions of city and country, Borges proposes to talk about the "arrabal" region, which translates a certain meaning of frontier, delineated by "fights and guitars" between the pampa and Buenos Aires. Once this new frontier is established, he tries to write about the ambiguous human being who lives in that region: the compadrito - a mix of the urban man and the gaucho. This compadrito belongs to a place which cannot be completely delimitated; he is intended to be not only a representation of Argentina's culture characteristics, once his identity is often migrating between the I and the Other, thus making possible the listening to the voices of differences, therefore translating this frontier identity - the one that truly represents the very LatinAmerican self.

PALAVRAS-CHAVE: Jorge Luis Borges. Nacionalismo. Identidade. Tradução. Fronteiras.

Após as lutas pela independência, os países latino-americanos buscam definir e estabelecer uma identidade nacional. É, pois, precisamente, a busca pela definição de uma "argentinidade" que irá refletir-se na produção literária argentina, não apenas no período imediatamente posterior à independência do país (ocorrida em 1810), mas também adentrando o século XX e perpassando a obra de um de seus filhos mais ilustres: Jorge Luis Borges. No entanto, a tentativa de definir uma identidade constituiu discursos ambivalentes, tendo cada um interpretado a história do país à sua maneira.

$\mathrm{Na}$ construção de uma identidade ergue-se a necessidade de uma fronteira entre o eu e o outro. Sendo o latinoamericano o outro do europeu, restava-lhe perguntar, então, quem haveria de ser o seu outro: à procura de uma resposta, estabeleceram-se fronteiras sob os limites do próprio país, buscando-se identidades que teimam em não se deixarem definir, acarretando a necessidade de diferentes representações: primeiramente a fronteira entre a pampa ${ }^{\text {iii }} \mathrm{e}$ a cidade dá o tom das obras de Sarmiento e Hernández - aquele aspirando a uma identidade argentina civilizada e urbana, contrária a barbárie do campo; este cantando a pampa e o gaucho como uma existência livre, oposta ao mundo urbanizado.

Considerada um dos textos fundadores da Literatura argentina, a obra Facundo (1845), escrita por Domingo Faustino Sarmiento, procura a definição de uma identidade nacional através do estabelecimento de uma fronteira entre civilização e barbárie, apontando para a existência de duas sociedades rivais e incompatíveis: a pampa bárbara e a cidade civilizada. Assim, para Sarmiento, os problemas do país justificavam-se pela existência da pampa e do povo que nela habitava. Sendo o homem um produto do meio, um ambiente hostil como o deserto dos campos no qual se encontram presentes a resignação para a morte violenta, a insegurança e a solidão, não poderia originar outra espécie de indivíduo que não fosse o bárbaro ilustrado pela figura do caudilho Facundo Quiroga e o cruel ditador Rosas. Portanto, Sarmiento é categórico ao afirmar que, para que a civilização viesse a imperar um dia naqueles descampados argentinos, fazia-se necessário derrotar o gaucho - principal representante da barbárie - expulsando-o das províncias, educando os jovens e "importando" imigrantes europeus para a povoação do país. Era, pois, imperativo liberar o povo argentino do passado medieval e bárbaro herdado da decadente cultura espanhola, da "servil raça negra e da selvagem raça indígena" (ZEA, 1989, p.89). O estabelecimento dessa fronteira entre o gaucho bárbaro e o portenho civilizado exigia a negação de um passado tanto americano quanto espanhol, eis que a civilização, identificada por Sarmiento nas culturas francesa e norte-americana, deveria impor-se sobre o mundo bárbaro.

\footnotetext{
* Denise Vallerius de Oliveira é mestranda em Literatura Comparada pela Universidade Federal do Rio Grande do Sul. Orientadora: Profa. Dra. Patrícia Lessa Flores da Cunha (UFRGS).
} 
Embora contrário à identificação da pampa com a barbárie, José Hernández, ao escrever El gaucho Martín Fierro (1872), contínua mantendo a fronteira entre cidade e campo. No entanto, se para Sarmiento a identidade argentina a ser buscada encontrava-se nos valores do homem e da vida urbana, sendo o homem do campo o seu outro a ser combatido, para Hernández a verdadeira argentinidade encontrava-se no homem e nos valores preservados pelo campo, estando a barbárie representada pela cidade e pelo indígena. Como bem nos lembra Borges, o objetivo de Hernández era denunciar a política de conquista das fronteiras instauradas no país, formando-se um exército com função penal cuja composição compreendia "malfeitores e gauchos" arbitrariamente arrebatados pelas "caçadas" policiais e cujo objetivo era lutar contra os índios. O gaucho Martín Fierro é, pois, vencido por uma civilização que "devendo ser própria, americana, produto do gênio da raça para poder conciliar-se com a alma da população do país, era barbaramente destrutiva, européia e desargentinizante" (MASSEY, 1969, p.9). Hernández apontava, com isto, que bárbaro não era o gaucho, mas o homem urbano cuja autoridade era imposta campanha afora, devendo aquele a ela submeter-se ou então desaparecer; bárbaro era, então, o projeto de Sarmiento.

No entanto, ambos projetos procuravam negar tanto a identificação com a Espanha colonizadora quanto com a herança da cultura autóctone, originando uma situação de completa alteridade que, segundo Miriam Volpe [s/d], marcou profundamente a problemática da identidade latino-americana, eis que ao não pertencer nem ao passado indígena e nem à Espanha, era-se parte da nação sem o ser totalmente. Ou seja, estava-se dentro, mas concomitantemente também se estava fora - o que caracterizava uma inegável situação fronteiriça. Não obstante, na busca por uma identidade argentina, tanto Sarmiento quanto Hernández parecem não se permitirem identificar também como alteridade, negando sua condição de seres fronteiriços. A busca dessa identidade, da definição de um $e u$, impele à identificação de um outro que me é inferior, devendo, portanto, ser combatido. Na sua situação de latino-americanos, sendo sempre vistos como um outro do europeu, parecem não quererem assumir essa alteridade, delegando-a ao que lhe é diferente dentro do próprio território: o bárbaro ao qual nunca me identifico (para Sarmiento, bárbaro é o gaucho; para Hernández, a inumanidade da cidade e o indígena).

Não há, portanto, novidade ao afirmarmos que a produção literária latino-americana bem como sua respectiva crítica sempre estiveram, de alguma forma, voltada para a Europa e para os cânones por ela instituídos. Observa-se, portanto, um paradoxo na medida em que, ao lado de uma visão eurocêntrica vigorava, também, o nacionalismo. A pergunta que se instaura, então, é como a busca por uma literatura e uma identidade genuinamente argentina (e, por extensão, latino-americana) pretendidas por Sarmiento e Hernández poderia ser compatível com um constante sentimento de dívida para com o europeu? Tal paradoxo faz-se presente após a delimitação das nações sob o limite de fronteiras que originaram consciências nacionais, determinando identidades a partir do estabelecimento de uma diferença (que não existia anteriormente) entre os "outros" que só pode tornar-se realidade através do discurso elaborado pelo "nós" criando dentro destas fronteiras. A nação constitui-se, portanto, conforme designou Benedict Anderson, em uma "comunidade imaginada" originada a partir da postulação de uma identidade comum , na qual o sujeito vive sua identidade pessoal como se ela fosse compartilhada com os demais indivíduos que constituem sua nação (VOLPE, [s/d], p. 64-65).

Assim, essa dicotomia apresentada entre nacionalismo e eurocentrismo pode ser explicada pela ambivalência constitutiva de todo discurso nacionalista e pela posição contraditória assumida pelos intelectuais dos países colonizados, atravessados por ideais, muitas vezes, antagônicos. Para Bravo (2000), o sujeito nacional das culturas pós-coloniais possui uma voz cindida, um rosto com duas faces: uma que olha para o seu povo e a outra que olha para a metrópole. Assim, o nacionalismo argentino e latino-americano seria culturalmente colonial e politicamente anticolonial. Ou seja, seria culturalmente filiado a posições européias e politicamente anticolonial quando capaz de entender a cultura nacional como um instrumento para construir uma identidade independente e crítica acerca das estruturas de dominação colonial. No entanto, a primeira face implica uma visão racista sobre as minorias étnicas da nação, como bem nos atestam os exemplos que Sarmiento e Hernández prodigamente oferecem-nos em suas obras. Aquele, embora analise tangencialmente a questão racial em Facundo, apresenta os índios como selvagens, os gauchos como bárbaros que desenvolviam apenas suas qualidades físicas e os criollos como homens que se entregavam a seus instintos quando na campanha. Mas é na sua obra de 1883 intitulada Conflicto y armonia de las razas en América que o seu horror à mestiçagem não procura dissimulações, apontando-a como uma degradação social que originava povos avessos a democracia, além de identificar as raças negra e indígena como inferiores.. Não muito distante disso, Hernández também apresenta em sua obra uma clara aversão ao indígena e ao negro, eis que nos apresenta versos como

A los blancos hizo Dios,

A los mulatos San Pedro,

A los negros hizo el diablo

Para tizón del infierno (HERNÁNDEZ, 2001). 
Também Anthony Smith (2000) apresenta-nos uma interessante classificação das funções que cabe ao nacionalismo exercer. Segundo o teórico, ele deve desempenhar um papel de redescobrimento, de reinterpretação e de regeneração da comunidade. O redescobrimento consistiria em buscar a "etno-história" autêntica da nação através de uma nova coleção de mitos e tradições, da investigação e da localização de novas fontes da cultura nacional (para Sarmiento, o mito da civilização localizada em Buenos Aires; para Hernández, o mito do gaucho). Já o papel da reinterpretação seria o de selecionar as tradições fixando o cânone da "etno-história", selecionando mitos e lembranças com a finalidade de instalar a comunidade em um contexto significativo. O passado étnico seria reinterpretado para que os anseios nacionalistas do presente pareçam autênticos, naturais e compreensíveis. Mas assim como o passado deve ser selecionado e interpretado sob uma luz especificamente nacional, também o presente é interpretado seletivamente, de acordo com uma ideologia de autenticidade nacional. Destarte, o nacionalismo postula a necessidade de um passado eminentemente glorioso. Já a função de regeneração consistiria em uma mobilização coletiva através da exploração das emoções do povo, inspirando-lhe um fervor moral e ativando suas energias em prol de metas nacionais, com a finalidade de reformar e renovar a comunidade. Isto posto, percebe-se que, sob o enfoque do nacionalismo,

[...] o passado não consiste em uma mescla de ingredientes combinados caprichosamente por inclinação artística, nem em canteiro de materiais culturais com o qual os construtores de nações inventam nações, nem sequer em uma sucessão de épocas sobre cujo cimento a moderna nação descansa firmemente. $O$ passado [...] compõe-se de uma série de tradições e lembranças que estão sujeitas a constante interpretação (SMITH, 2000, p.203).

Reforçando esse caráter ambivalente do nacionalismo, Célia Pedrosa (1992), em seu ensaio Nacionalismo Literário, atenta para o fato de que toda forma de linguagem permite e obriga a dizer simultaneamente, criando possibilidades, estabelecendo códigos, institucionalizando mecanismos de organização e exclusão. A literatura teria sido vista, então, como importante instrumento na luta pela autonomia política e cultural, direcionando-se para a definição e valorização de uma realidade especificamente argentina. Estimulou-se, assim, o interesse pelo passado (a reinterpretação, proposta por Smith) e o resgate de autores (regeneração) que passaram a ser considerados fundadores da tradição literária, havendo a preocupação em representar a genealogia, o caráter e a natureza do país. Tal fenômeno constata-se, principalmente, conforme assinala Sarlo (1998), na interpretação realizada por Lugones em 1916 do Martín Fierro, apresentando-o como um épico nacional comparável aos poemas homéricos, interpretando sua personagem como símbolo de virtude e de valores tipicamente argentinos. Tal fundação mítica da nacionalidade era possível devido ao fato de que os gauchos (enquanto povo rural livre e pobre que não havia sido totalmente incorporado ao mercado de trabalho, mas levado a ele segundo as necessidades da exploração rural, ou recrutados para o exército e destinados à fronteira com os índios) já não existiam. Para Sarlo, a invenção de Lugones era duplamente oportuna, uma vez que não comprometia ninguém em termos sóciopolíticos e, ao mesmo tempo, o gaucho poderia ser visto como símbolo de uma essência nacional ameaçada pela imigração, provendo, então, as bases de uma reorganização mítica da história e um modelo de identidade também imaginado. Assim, a elite crioula transformou Fierro em uma figura nacional, ignorando sua rebeldia e as injustiças por ele cometidas, enquanto os imigrantes anarquistas consideravam-no um modelo de insurgência social. Cristaliza-se, pois, em ideologia estética e política a partir do momento em que a identificação das especificidades torna-se pretexto para a propagação de um discurso ufanista, procurando dissimular as diferenças e problemas, sendo a autenticidade confundida com o exotismo e com a cor local.

No entanto, a busca pela afirmação enquanto síntese do que representaria uma essência nacional acarreta a negação de uma tradição que, ao mesmo tempo, é reinterpretada na tentativa de preencher o vazio com narrativas, imagens e idéias que contribuiriam para a formação de mitos fundadores da nacionalidade. Nesta perspectiva, Pedrosa (1992, p.291) afirma que a literatura latino-americana "autenticamente" nacional e nacionalista alimentavase de um ideário filosófico / político alemão e francês, servia-se da língua das metrópoles e de formas cunhadas pelo romantismo europeu, como o romance histórico, fazendo com que uma origem fosse moldada alheia aos valores da cultura autóctone. Simultaneamente ao conveniente "esquecimento" de todas as práticas impossíveis de serem compreendidas pela mentalidade civilizada, providenciou-se o tratamento estético que ressaltava o caráter exótico das práticas que escapavam à censura. Assim, a exaltação ufanista acabava correspondendo às expectativas que o etnocentrismo impunha ao olhar europeu, incapaz de perceber a alteridade das sociedades primitivas, capazes de despertar apenas a sua curiosidade ou suscitar o empenho civilizador. Conforme Parekh (2000), tratava-se, não obstante, do fato de que para grande parte das teorias nacionalistas, uma comunidade não poderia constituir-se nação se estivesse interessada em acomodar diversidades culturais profundas ou se fosse hospitaleira com elas.

A tentativa de definir uma identidade sem fissuras, objetivando a demarcação de uma identidade genuinamente nacional, percorreu um caminho que levou às armadilhas da contradição que um discurso de cunho nacional impõe a qualquer país. Afinal, o "nós", construído a partir do que não é o "nós', gerado com a descolonização, nunca é um sujeito definível em termos simples. Pelo contrário, é sempre mais fácil definir-se como 
não europeu, ou como não argentino, por mais que a história cultural nacionalista tenha buscado manter o vínculo entre cultura e nacionalidade, eliminando todo desajuste e toda assimetria. As temporalidades desiguais que coabitam a nação podem aflorar apenas com a ajuda de uma leitura crítica da identidade que permite contrastá-las tanto com as histórias homogeneizadoras narradas pelos centros metropolitanos como com perspectivas periféricas que tendem a reproduzir essas leituras em nível local, mediante a construção de relatos unânimes em nome da unidade nacional (GEERTZ apud BRAVO, 2000).

Resta-nos perguntar, agora, como estabelecer-se-ia uma identidade a partir do momento em que as fronteiras territoriais já foram conquistadas e asseguradas, a partir do momento em que o indígena já fora combatido e o gaucho tornara-se um mito sobrevivente apenas na obra de Hernández, mas cujos motivos de luta perderam-se com a marcha do progresso. Não havendo mais a necessidade de defesa e de demarcação das fronteiras, eis que o Estado assume este papel, o gaucho perde seu papel de guerreiro, daquele que luta contra a opressão civilizatória e contra o índio. Da mesma forma, a capital Buenos Aires não vê mais o gaucho como um inimigo bárbaro a ser combatido, uma vez que este fora assimilado pela civilização. Acaba-se, assim, borrando-se a fronteira entre civilização e barbárie que possibilitava sempre a identificação de um outro oposto a um eu que reclamava para si a argentinidade.

Essa dicotomia civilização versus barbárie fazia com que cada um dos pólos reclamasse para si sua condição de centro, estabelecendo um discurso sobre a fronteira (entre o eu e o outro), mas nunca um discurso na fronteira - o que nos permitiria ultrapassar o local para atingir o universal, eis que, justamente por sua condição de entre-lugar no qual se estabelecem contatos e trocas, a fronteira lê-se como locus híbrido. Segundo Pesavento (2002), a fronteira constitui-se em uma realidade transcendente, em um limite sem limites apontando para um além. Trata-se, portanto, de um conceito impregnado de mobilidade que proporciona o surgimento de algo novo e diferente, mas que se faz ambivalente uma vez que, sendo trânsito, comporta dois estados de ser. Concomitantemente, ela também se faz ambígua ao trazer consigo uma promessa de superação no tempo e na possibilidade de ser um outro, de ser um terceiro que transcende o localismo pela perda de sua territorialidade - o que nos permite atingir o valor universal da fronteira.

Justamente a fronteira como valor universal é designada por Abril Trigo (apud VOLPE) como "fronterías", antigo sinônimo espanhol para "fronteira", que indicava o ato de criar novas frentes, de construir e abrir caminhos. Ela não seria, portanto, uma linha, mas sim um espaço fronteiriço no qual predomina a ação, a mobilidade e o avanço. Não seria mais conveniente, pois, o discruso sobre a fronteira (identificado com o próprio termo), mas na fronteira (identificado com o termo "frontería"),

[...] porque la frontera define territórios, la frontería dibuja paisajes; la frontera fija identidades, la frontería abre relaciones; la frontera delimita espacios, la frontería articula lugares; la frontera hunde raíces, la frontería esparce un rizoma; la frontera legisla la razón del Estado, la frontería es indiferente a la Nación; la frontera es marca de la Historia, la frontería habilita memórias fragmentadas (TRIGO apud VOLPE, [s/d], p.71).

Assim, na contramão da relação binarista, hierarquizante e excludente estabelecida pela lógica nacionalista na qual um termo opõe-se ao outro, surge a obra de Jorge Luis Borges estabelecendo justamente um discurso de "fronterías" "que não legisla a razão do Estado". Muitos são os exemplos nos quais o escritor apresenta-nos a falácia da crença em uma identidade e expressão literária puras, que suplantem as diferenças e neguem os cruzamentos culturais que sustentam a verdadeira identidade latino-americana: a de seres fronteiriços que possuem a liberdade de transitar entre o que é próprio e o que é alheio. Tanto é assim que Borges utiliza um texto considerado símbolo da identidade argentina a fim de demonstrar o quão heterogêneo ele o é. Trata-se, pois da obra Don Segundo Sombra, escrita por Güiraldes, que, segundo Borges, ao ser comparada com as obras da tradição gauchesca, evidencia muitas diferenças, uma vez que a primeira é pródiga em metáforas de uma espécie que nada tem a ver com a fala do campo, e sim com as metáforas dos cenáculos de Montmartre. No que concerne ao enredo, é fácil comprovar nele a influência de Kipling, cuja ação se situa na Índia e que foi escrito sob influência de Huckleberry Finn de Mark Twain. No entanto, o escritor afirma que, ao fazer essa observação não quer

[...] diminuir o valor de Don Segundo Sombra; ao contrário, [quer] ressaltar que para que nós tivéssemos esse livro foi necessário que Güiraldes recordasse a técnica poética dos cenáculos franceses de seu tempo, e a obra de Kipling que lera há muitos anos; ou seja, Kipling, e Mark Twain, e as metáforas dos poetas franceses foram necessários para esse livro argentino, para esse livro que não é menos argentino [...] por ter aceitado essas influências (BORGES, 2001- c, p. 292-293).

Por conseguinte, ao produzir sua ficção, Borges também busca dar voz a personagens que não reclamam a posição de centro, mas que se caracterizam justamente por serem seres fronteiriços que abolem a oposição entre civilização e barbárie, cidade e pampa, o eu e o outro para representarem a impossibilidade de uma identidade una e homogênea. Aponta-se, pois, para uma identidade movente que não pode ser caracterizada por relações que se estabelecem através do conetivo "ou", pois este exprime a incompatibilidade dos conceitos envolvidos. A identidade do ser fronteiriço passa, então, a ser caracterizada por relações que se estabelecem através do conetivo " $e$ ", eis que este não mais exclui, mas está a indicar uma relação de adição e complementação. Instaura-se, assim, uma nova 
lógica na qual o eu é já, também, o outro. Por isso, Borges escolhe como símbolo dessa condição fronteiriça não mais o gaucho e a pampa argentina; tampouco escolhe o homem "civilizado" da cidade, mas sim o homem dos arrabaldes de Buenos Aires, o "orillero" do sul que não pertence nem ao campo e nem à cidade e, exatamente por sua condição de não pertencimento, consegue transitar entre o civilizado e o bárbaro, constituindo-se num ser híbrido por excelência.

No entanto, esta proposta de Borges nem sempre foi bem interpretada, havendo a crítica, muitas vezes, dado pouca importância ou até mesmo rechaçado os contos e ensaios nos quais predomina a temática regional. Afinal, Borges era reconhecido como autor de uma obra de temática universal com a qual a discussão de questões locais / regionais pouco combinava. Melhor, então, olhar para estes textos como um mero exercício estilístico do escritor, quando ainda procurava o verdadeiro tom de sua magnífica obra e onde a preocupação com a língua "argentina", com a gauchesca e com os "orilleros" não passava de mero arroubo nacionalista de um jovem que há pouco havia retornado a seu país. Porém, se nos debruçarmos sobre estes textos com um pouco mais de cuidado, veremos que tanto ao discutir a questão do idioma quanto ao dar voz às minorias, Borges reconhece o sincretismo cultural de seu país; a tensão existente entre espaço nacional e espaço europeu, rompendo com a possibilidade de uma identidade nacional originária. Opta, pois, por escrever uma literatura não mais $d a$ fronteira, mas $n a$ fronteira, no limite, na margem do híbrido que lhe permite não ser devedor de um discurso nacionalista e tampouco de um discurso de dependência cultural européia. Escrevendo $n a$ fronteira, alimenta-se das diferenças possibilitando o surgimento de algo novo; escrevendo na fronteira, assume sua condição de latino-americano, afinal "não somos europeus nem americanos do norte, mas destituídos de cultura original, nada nos é estrangeiro, pois tudo o é. A penosa construção de nós mesmos se desenvolve na dialética entre o não ser e o ser outro" (GOMES apud SANTIAGO, 1978).

Portanto, para Borges, escrever na fronteira é traduzir: implica um movimento de leitura e interpretação do que é próprio e do que é alheio; implica um contínuo movimento de retorno ao outro e ao seu insólito, havendo também contínuos movimentos de retorno sobre o seu "eu", caracterizando um trânsito onde ocorrem reconfigurações: a cada movimento de retorno, as impressões e percepções de cada passagem não são apagadas, mas sim superpostas. Não obstante, podemos nos valer da posição assumida por Jacques Derrida (1999, p.62) que, ao ser interrogado se acreditava que seus textos traduzidos diziam o mesmo que os textos franceses, afirmou: "os textos traduzidos nunca dizem as mesmas coisas que os textos originais, sempre ocorre algo de novo; o paradoxo da tradução é o fato de que um texto traduzido chega à outra coisa, mas outra coisa que está em relação consigo mesma". E poderíamos, por extensão, acrescentar que o paradoxo de uma escrita realizada na fronteira é criar algo novo (transcendendo, assim, o local e logrando atingir o universal), mas que ao mesmo tempo não exclui o lugar de origem que é sempre revisto, reinventado e renovado - eis que necessito realizar uma travessia em direção à estranheza do outro. Assim, quanto maior a estranheza, maior é a consciência da alteridade e, por conseguinte, maior a certeza de que ela não está apenas no outro, mas também em mim. Ao assumir a margem como locus de enunciação, Borges reconhece que esta condição privilegiada permite "descobrir as suas incoerências e os seus abismos, em suma, as suas 'estranhezas', [...] a questão volta a se colocar: não mais a da acolhida do estrangeiro no interior de um sistema que o anula, mas a da coabitação desses estrangeiros que todos nós reconhecemos ser" (KRISTEVA, 1994, p.10).

Voltemos a falar, então, sobre a temática do subúrbio de Buenos Aires na obra de Borges como exemplo desse espaço fronteiriço utilizado para traduzir (reler e recriar) uma tradição nacional que acaba atingindo foros de universalidade. As "orillas" conformam-se como local ambíguo no qual se apagam os limites entre os campos que circundam a cidade e as primeiras casas, localizando-se ao sul da metrópole. Para Borges, "o termo las orillas ajustase com sobrenatural precisão a esses pontais escassos, em que a terra assume a indeterminação do mar" (2001- d), havendo, no poente, becos empoeirados e uma brisa quase confidencial que inaugurava mal e mal a pampa, chegando-se então ao Arroio Maldonado. O rio é apontado como a fronteira que, há décadas atrás, estabelecia o início do mundo feito de "relinchos e crinas e pasto doce", mas que agora se tornara território de arrebaleiros, de uma comunidade gringo-crioula na qual predominavam os galpões de zinco, chamados de salões, o tango, e onde um compadrito sempre amanhecia morto com uma punhalada. Os subúrbios portenhos assumiam, assim, um caráter provisório oriundo "da dupla gravitação da planície chacareira ou eqüestre e da rua de sobrados".

No conto que transita entre o real e o fantástico intitulado $O \mathrm{Sul}$, o escritor brinda-nos com outra definição dessa fronteira: "Ninguém ignora que o Sul começa do outro lado da rua Rivadavia. Dahlmann costumava repetir que isso não é uma convenção e que quem atravessa essa rua entra num mundo mais antigo e mais duro" (2001-f, p.586). Dahlmann é personagem emblemática, pois, embora viva na cidade, apresenta a ambivalência fronteiriça que congrega dois estados de ser: a descendência de um avô paterno culto, europeu, pastor evangélico e, portanto, homem da "civilização"; e a descendência de um avô materno que morrera lutando com os índios pela conquista do território - um gaucho, portanto. Após um difícil período de convalescença em um hospital (fato que ocorre no plano real), havendo estado muito próximo da morte, decide voltar ao Sul onde ainda conservava uma estância que fora de 
seu avô materno, sendo aí morto em um duelo de facas com um compadrito (fato que ocorre no plano do fantástico). Ao final do conto, temos a declaração do narrador de que se Dahlmann "tivesse podido escolher ou sonhar sua morte, esta é a morte que teria escolhido ou sonhado". Este conto pode ser lido como uma metáfora da situação fronteiriça do homem latino-americano. Note-se que a personagem não aceita passivamente uma identidade urbana - a qual deve-se a questões circunstanciais e não a uma escolha. Propõe-se, então, percorrer o caminho que lhe possibilite construí-la autenticamente, necessitando, para isto, deslocar-se (mesmo que seja no plano do imaginário) até o "Sul” - fronteira entre o eu e o outro, entre o mundo civilizado e o bárbaro, entre as planícies do campo e a cidade. Escolhe a morte nessa fronteira e não na cidade; rechaça a identidade que lhe é dada como certa, estável e livre de conflitos para abraçar a tensão que emana da fronteira e que lhe permite reconhecer-se uma identidade fragmentada. A identidade de Dahlmann, assim como a de todo latino-americano, não se conforma no discurso que nos deseja definir como extensão do europeu (representado pelo mundo urbano) e nem com o exotismo de algo que pretensamente define-se como genuinamente nacional (representado pelas planícies da pampa e o gaucho transformado em herói épico). Ao situar-se na fronteira, num entre-lugar, acolhe tanto o bárbaro quanto o civilizado, reconhece tanto sua herança européia quanto sua herança indígena, negra, gaucha. E essa fronteira deslizante, essa margem que não é um "além" prescrevendo limites, também não é um "fora" que está em oposição a um "dentro", pois "o limite é violentado, rasura-se, perde-se; o próprio e o outro jogam; a perda é o encontro” (SANTIAGO, 1976).

Em 1935 Borges publica o conto Hombre de la Esquina Rosada, no qual o narrador é um compadrito das "orillas" contando a Borges e a outros habitantes mais jovens da região a história de um tempo em que essa fronteira entre a cidade e a pampa era feita de lutas e guitarras, sendo que o uso da faca determinava seus heróis. Interessante atentarmos para o fato de que, embora o conto não mencione em que local a história está sendo narrada, o título indica-nos a esquina, local típico da tradição oral e popular e, também, uma espécie de fronteira na qual não apenas as pessoas se cruzam, mas também os discursos e as histórias ali contadas. Assim, o sujeito que se encontra nessa esquina-fronteira assume o papel de tradutor das histórias que ali chegam, lendo-as, interpretando-as e transformando-as em versão própria a fim de levá-las adiante.

Esse narrador, portanto, propõe-se a contar a "verdadeira" história sobre a morte de Francisco Real, compadrito mais conhecido como "Curraleiro". Francisco Real, que detinha o mando dos subúrbios ao norte da cidade, afronta os compadritos do "Sul", ao lá chegar com seus companheiros para beber, brigar e matar. O "Sul” era território de um dos mais famosos e valentes compadritos: Rosendo Juárez, mais conhecido como o Batedor, era respeitado e temido por todos, pois "ninguém ignorava que matara dois". Mas, para espanto de todos, quando o Curraleiro - que até então não passava de um desconhecido para os sulinos - desafia a coragem de Rosendo, que tinha "fama de ser bom na faca e durão", este se nega a brigar, atirando sua faca pela janela do galpão e indo embora. O narrador do conto, que testemunhara os fatos, fica inconformado com a covardia de Rosendo e com o fato de seus homens (dentre os quais o narrador) terem sido incapazes de responder à humilhação infligida pelo Curraleiro. Este é misteriosamente assassinado e, ao final do conto, o narrador revela indiretamente que fora ele o assassino a restaurar a valentia dos homens do Sul, após a vergonha da desistência de Rosendo: "Entonces, Borges, volví a sacar el cuchillo corto y filoso que yo sabía cargar aquí, en el chaleco, junto al sobaco izquierdo, y le pegué otra revisada despacio, y estaba como nuevo, inocente, y no quedaba ni un rastrito de sangre" (BORGES, 1989).

$\mathrm{O}$ encaminhamento dos fatos permite-nos observar que o Curraleiro, que apesar de haver sido esfaqueado longe do salão de baile, a ele retorna ainda com vida, podendo, pois, ter apontado o seu assassino que ali se encontrava a fim de que seus companheiros lhe vingassem a morte. Mas, então, por que não o fez? O motivo talvez se encontre no narrador. Lembremo-nos que ele é o homem da esquina, e as atitudes e falas das personagens nos são conhecidas através da sua voz, da sua tradução dos fatos, possivelmente adequada aos seus interesses.

Surpreendentemente, trinta e cinco anos mais tarde, na obra El informe de brodie, encontraremos o conto Historia de Rosendo Juárez que nada mais é do que a versão de Rosendo, o Batedor, que não aceitara lutar com o Curraleiro. Nesse conto encontramos dois narradores: um é a personagem Borges, que tem mencionada sua profissão de escrever ficções e que não participa da história contada; e o outro é o próprio Rosendo que, muitos anos depois, encontra-se com Borges em um antigo armazém (que no tempo na narração já havia transformado-se em um bar) para contar sua história:

Usted no me conoce más que de mentas, pero usted me es conocido, señor. Soy Rosendo Juárez. El finado Paredes le habrá hablado de mí. El viejo tenía sus cosas; le gustaba mentir, no para engañar, sino para divertir a la gente. Ahora que no tenemos nada que hacer, le voy a contar lo que de veras ocurrió aquella noche. La noche en que lo mataron al Corralero. Usted, señor, ha puesto el sucedido en una novela, que yo no estoy capacitado para apreciar, pero quiero que sepa la verdad sobre esos infundios (BORGES, 2001- a.).

Rosendo passa a ser o narrador da história e, reconhecendo Borges como um escritor que havia "puesto el sucedido en una novela", preocupa-se em dar a sua versão dos fatos, em apresentar a sua verdade. No entanto, é interessante notar que Borges não ficou sabendo da história através de Nicolas Paredes - que é mencionado pelo narrador do conto anterior como um dos chefes de Rosendo - mas pelo narrador e matador de Francisco Real, cuja 
identidade ignoramos. Logicamente que este fato não impediria que Borges também houvesse conversado com Dom Nicolas, tendo dele também recebido uma versão da história. Isso indica que também podemos vir a desconfiar da versão da história dada pelo próprio Borges, pois escrevera "infundios" a partir do que o compadrito que matara Francisco ou do que o cacique político da região, Dom Nicolas, contaram-lhe, sem haver investigado o fato suficientemente antes de traduzí-lo em seu conto. Rosendo ignora, porém, que a sua versão dos fatos também pode não ser a verdadeira, uma vez que cada um conta a verdade da maneira que lhe convém. Na versão dada por Rosendo, ele não havia se negado ao desafio de luta proposto pelo Curraleiro por covardia ou por se sentir ameaçado pelo homem que tinha a coragem de desafiá-lo. Nega-se a lutar simplesmente porque se vê refletido em Francisco como em um espelho, decidindo que não valia a pena seguir aquela vida de mortes e brigas: "Sucedió entonces lo que nadie quiere entender. En ese botarate provocador me vi como en un espejo y me dio vergüenza. No sentí miedo; acaso de haberlo sentido, salgo a pelear". A versão de Rosendo inverte os papéis: segundo ele, a coragem estava em deixar a vida que levava, não se importando com o que os outros viessem a pensar dessa atitude, ao passo que o covarde da história seria o compadrito narrador de Homens da Esquina Rosada, uma vez que teria matado Francisco Real à traição.

Note-se que se no conto anterior o local no qual os fatos estavam sendo narrados a Borges era uma esquina, em História de Rosendo Juárez este local é um armazém - apresentando funções semelhantes às da esquina -, constituindo-se em espaço da tradição oral, locus de entrecruzamento de diferentes histórias e opiniões - fronteira, portanto, de onde Borges traduz diferentes vozes. Essa fronteira constituída de oralidade "democratiza o sujeito de história e cultura no sentido de fornecer um foro público onde pessoas, que em outras circunstâncias estariam silenciadas, podem falar" (RIMSTEAD, 2000, p.265). Por isso, ao elaborar seus contos, Borges coloca-se na fronteira, posição que lhe permite traduzir histórias alheias - princípio, aliás, que irá reger sua poética de composição do início ao fim.

Cabe, pois, assinalarmos brevemente a maneira como Borges concebe o ato tradutório (discurso que se dá na fronteira) para a compreensão não apenas de sua produção literária, mas também como metáfora da condição fronteiriça de todo o latino-americano. Tendo utilizado o princípio da tradução como preceito básico no qual se sedimenta grande parte de seus textos, surpreendeu críticos mais conservadores que viam no seu labor artístico uma afronta ao que se poderia esperar de um escritor argentino. É, portanto, exemplar a crítica feita pelo escritor argentino e nacionalista Ramón Doll (apud HELF \& PAULS, 2000) que, em artigo de 1933, designa a obra de Borges como "parasitária", eis que repetia mal o que os outros disseram bem, acusando-o de apresentar Dom Quixote e Martín Fierro como inéditos para mostrar aos leitores o quanto ele era unilateral, uma vez que respeitava todas as idéias. De acordo com Doll, Borges repetia e degradava aquilo que repetia; não se limitava a reproduzir textos de outros, mas o fazia imoderadamente, como se nunca houvessem sido publicados. No entanto, ao longo de sua trajetória como escritor, o mesmo Borges assume o seu papel de "parasitário", pois qual escritor não o seria? Afinal, grande parte de sua obra está, segundo Helf \& Pauls (2000), nessa relação em que o escritor chega sempre depois para ler, comentar, traduzir ou introduzir uma obra ou um escritor que aparecem como primeiros, como originais. É, esse, portanto, um dos axiomas básicos em que descansa a política borgeana: "repetir mal o que os outros disseram bem". Há sempre, portanto, a repetição da consigna de História Universal da Infâmia: falsificar e deturpar histórias alheias, pois

[...] los principios de los cuentos de Borges son tan infalibles como el 'Había una vez' de las ficciones infantiles: 'Cuentan los hombres dignos de fe'; 'De las historias que esa noche me contó, me atrevo a reconstruir la que sigue'; 'En Junín o en Tapalquén refieren la historia'; 'Dicen que la historia fue referida por Eduardo, el menor de los Nelson'; 'Hace ya tantos años que Carlos Reyles me refirió la historia en Agrogué'; 'En un ejemplar del primer volumen de las Mil y Una Noches descubrimos el manuscrito que ahora traduciré al castellano'. [...] Borges rara vez se presenta en sus relatos como el inventor de una historia; su función, más bien, consiste en recibirla de otro, escucharla o leerla, como si el primer paso para contar una historia fuera ser su destinatario ( HELF \& PAULS, 2000, p.112).

Para um leitor desavisado, o narrador borgeano parece não ter nada de próprio, nada daquilo que se esperaria de um autor. No entanto, o que Borges se propõe, propõe a toda criação artística e também para pensarmos o lugar do latino-americano em meio a uma tradição que identifica o europeu (e mais recentemente o norte-americano) como valor universal, é descobrir o que fazer com o que já existe. Talvez a sua precoce experiência com o bilingüismo, possibilitando-lhe uma simultaneidade entre o inglês (língua paterna) e o espanhol (língua materna), seja uma das justificativas para o surgimento de um escritor expatriado que, abolindo diferenças entre língua primeira e língua segunda, entre original e versão, incorpora uma nova espécie de "parasita", como Doll insistiu em chamá-lo: os "tradutores infiéis" que, segundo Helf \& Pauls, não deixam de vampirizar o organismo ao qual estão aderidos. Além disso, levam a vampirização até as últimas conseqüências quando, embriagados de sangue alheio, traem a condição da sua espécie e produzem algo novo. 
É neste sentido que Susan Bassnett (1993) sinaliza para o fato de que os estudiosos africanos, indianos ou latinos conseguem reler e repossuir a literatura canônica européia uma vez que formulam suas concepções a partir de uma base ideológica diferenciada, tomando como ponto de partida não uma idéia abstrata do belo universal e transcultural, e sim as necessidades imediatas de suas próprias culturas. E é justamente essa posição de escritor das margens que possibilita a Borges vislumbrar a literatura como sendo a sua pátria, pois o seu exotismo e o seu nativismo consistem precisamente em ser estrangeiro a todas as literaturas por ser nativo apenas da literatura, sem qualitativos geográficos ou históricos (MONEGAL, 1997). A pergunta que Borges se faz é, exatamente, como escrever literatura em uma nação culturalmente periférica, sem fortes tradições culturais próprias. A solução por ele encontrada é realizar uma obra que não se localiza em parte alguma, uma obra fronteiriça perturbada pela tensão da mescla e pela nostalgia por uma literatura européia que, segundo Sarlo (1998), um latino-americano nunca vive totalmente como natureza original. Da periferia imagina uma relação não dependente com a literatura estrangeira e consegue fazer com que sua literatura dialogue de igual para igual com o restante da literatura ocidental, fazendo da margem uma estética.

Assim, além do convívio com o bilingüismo desde a sua infância, esta sua situação de um escritor que se estabelece na fronteira para elaborar seu discurso, possibilita-lhe olhar a literatura e, sobretudo, a tradução, sem os preconceitos e valores culturalmente arraigados de seu tempo, não compactuando com a tradição logocêntrica, que logrou sobreviver até a segunda metade do século XX, na qual predominava a crença na possibilidade do transporte de significados únicos e estáveis de uma língua e cultura para outra sem perdas. Compactuar com tal teorização significaria compactuar com a idéia de que existe um texto, um discurso original que deve sempre ser preservado, delegando às suas traduções um papel de inferioridade e de subserviência. No entanto, o que Borges concebe é exatamente o contrário. Não concebe a literatura e a cultura como um sistema de credores e devedores, porque a originalidade é para ele uma falácia, uma ilusão daquele que diz, que escreve, que cria. Outrossim, a declaração que fez Borges certa vez, ao ter um de seus contos elogiados, ilustra a sua convicção na total impossibilidade da existência de um texto ou discurso que se pretenda original. Para ele, dever-se-ia falar em plágio, jamais em original, eis que o referido conto também teria sido

[...] plagiado como todos os meus. Plagiado da realidade, que, por sua vez plagiou um conto. Vivemos roubando. Roubando ar para respirar... Todo o tempo estamos recebendo coisas alheias... Não se poderia viver um minuto se não se estivesse recebendo. Mas também se dá algo, ou tratamos de dar algo (VÁZQUEZ, 1997, p.102).

Assim, assumindo-se como tradutor, aponta-nos que não há uma única versão possível, eis que não há texto definitivo e que não possa - e deva - ser apropriado por aquele que o lê. Destarte, os contos de temática local, cujas personagens localizam-se nesse entre-lugar que são os arrabaldes ao sul de Buenos Aires não estão na contra-mão do universalismo da obra borgeana. Ao contrário, Borges consegue aquilo que muito poucos escritores lograram: revelar o nacional sem ser nacionalista e o local sem ser localista. Daí que a temática regional na obra borgeana virá a ultrapassar os arrabaldes de Buenos Aires, reescrevendo textos emblemáticos da cultura Argentina ou utilizando-os como parte do enredo de seus contos. Lembremo-nos, pois, de contos como Biografia de Tadeo Isidoro Cruz e $O$ Fim nos quais Borges reescreve (em parte) o Martín Fierro de Hernández, não com o objetivo de reconhecer este texto como obra emblemática da argentinidade, de reconhecer o gaucho como um herói que encarna a identidade nacional, mas sim visando a exemplificar como aquilo que se pretende ler como genuinamente próprio de uma nacionalidade, atinge, através de um jogo intertextual e parodístico, foros de universalidade.

Desse modo, em Biografia de Tadeo Isidoro Cruz Borges ficcionaliza a vida do sargento Cruz, com a ressalva de que seu propósito "não é repetir sua história" (BORGES, 2001-b), pois ao narrador só lhe interessa uma noite, "o momento em que o homem sabe para sempre quem é". Para realizar esta reescritura da obra de Hernández, Borges também estabelece um diálogo intertextual com outros dois textos, a partir do momento em que utiliza como epígrafe do conto um trecho de Yets em The Winding Stair: "I'm lookink for the face I had before the worl was made". Além desta epígrafe, ainda no início do conto, deparamo-nos com a afirmação de que "a aventura consta de um livro insigne, quer dizer, de um livro cuja matéria pode ser tudo para todos (I Coríntios 9,22)”. Tanto a epígrafe quanto a passagem bíblica traduzem outro principio que perpassa as obras do escritor. Trata-se, pois, do duplo que se dá através do jogo de espelhos, refletindo o aspecto aparente do mundo, já que reproduzem uma realidade que não está neles, mas fora; podendo também ser considerados como metáforas da reflexão da consciência e da autocontemplação (MONEGAL, 1987, p.100). Essa reflexão da consciência dá-se tanto no apóstolo Paulo que, após ter uma "revelação", passa de perseguidor de cristãos a pregador do cristianismo (fato ao qual alude a passagem da Carta aos Coríntios mencionada por Borges), quanto no sargento Cruz, que deixa de ser o policial perseguidor do gaucho desertor e assassino Martín Fierro para tornar-se também um fugitivo. A insígnia do eterno retorno é, então, enfatizada através da comparação da história de Cruz com a de outros grandes personagens históricos: " Conta-se que Alexandre da Macedônia viu refletido seu futuro de ferro na fabulosa história de Aquiles; Carlos XII da Suécia, na de Alexandre. Tadeo Isidoro Cruz, que não sabia ler, [...] viu-se a si mesmo num entrevero e num homem." E, 
compreendendo que o outro era ele, compreendendo que seu destino era de lobo e não de "cachorro gregário", pôs-se a lutar contra os soldados ao lado de Fierro, como se não pudesse abandonar definitivamente as impressões da vida que levara antes de ser incorporado como membro da polícia rural - a vida de um gaucho que também fora perseguido pelas autoridades.

Note-se que a apropriação feita por Borges de um dos textos mais canônicos da literatura argentina, símbolo da gauchesca e, por conseguinte, representativo do espítito nacional que também calcava sua argumentação na oposição campo versus cidade e, por extensão, civilização versus barbárie, realiza-se com o objetivo de traduzí-lo (no sentido borgeano do termo), transformando-o num texto que pode ser significativo para qualquer povo. Ao enfatizar, através de sua reescritura do texto de Hernández, o fato de que todos os homens acabam igualando-se em suas atitudes, novamente está propondo um discurso que se dê $n a$ fronteira entre o eu e o outro, num terceiro espaço que impossibilita qualquer definição categórica. Se Cruz iguala-se a Fierro, como definir quem é o bárbaro e quem é o civilizado? Qual é a minha identidade e qual é a do outro? Findando seu conto com a constatação de que o eu é o outro, Borges aponta para o fato de que civilização e barbárie coexistem em qualquer ser, tempo e espaço. É, portanto, em vão perseguir e combater as diferenças porque são justamente elas que permitem ao homem compreender quem ele é, reconhecendo-se também como alteridade. Evoca-se, assim, a derrocada do discurso nacionalista que via no outro um inimigo a ser combatido.

Contra esse discurso, Borges também se manifesta através do conto O Fim, realizando novamente uma releitura da obra de Hernández. Na primeira parte desta, lembremo-nos que Fierro duela com um negro em um baile, assassinando-o. Já em A volta de Martín Fierro o irmão do negro assassinado, chamado Moreno, desafia Fierro para um duelo no intento de vingar sua morte. No entanto, este duelo dá-se através de uma payada não violenta, na qual Fierro novamente sai vencedor. Destarte, nas duas partes da obra, Fierro confirma sua superioridade sobre a raça negra. Todavia, em $O$ Fim, Borges escreve um final para a obra de Hernández, fazendo com que Fierro e o negro derrotado na payada reencontrem-se sete anos depois. Dessa vez, ao contrário do que ocorrera no desafio da payada no qual os filhos de Fierro e Cruz estavam presentes, o Moreno desafia Fierro para um duelo de vida ou morte, uma vez que este tinha uma dívida de sangue para com ele. O duelo termina com a morte de Fierro, ou seja, o negro venceu o branco. E novamente, como não poderia deixar de ser, o jogo de espelhos volta a apresentar-se: "Cumprida sua tarefa de justiceiro, agora era ninguém. Ou melhor, era o outro: não tinha destino sobre a terra e matara um homem" (BORGES, 2001-e). Na contramão do discurso nacionalista que apresentava uma visão racista sobre as minorias étnicas da nação, Borges iguala o destino de todos na figura de Fierro e do negro, que se fundindo um ao outro estão a apontar novamente para a fusão civilizado / bárbaro, eu / outro e não mais para a dicotomia excludente. Não procura, pois, estabelecer uma identidade argentina calcada na evocação de um passado heróico de gaúchos e nem no culto do forâneo como modelo a ser seguido, pois afirma não querer

[...] nem progressismo nem crioulismo na acepção corrente destas palavras. O primeiro é submeter-nos a ser quase norte-americanos ou quase europeus, num empenho em ser quase outros; o segundo, que antes foi palavra de ação [...], hoje é palavra de nostalgia[...]. Não cabe grande fervor em nenhum deles (BORGES, 1995, p.14).

Portanto, a tradição argentina não está nem em Sarmiento, nem em Hernández; não está na cidade (relacionada à identificação com a Europa) nem na pampa (relacionada com o exotismo do que se busca como tipicamente nacional); não está na civilização nem na barbárie. A tradição argentina estabelece-se na fronteira entre esses dois mundos: a cultura crioula ligada às tradições urbanas, letradas e européias. Conforme Sarlo (1998), nenhuma das duas pode ser repelida ou abolida por completo: nenhuma deve ser destacada a ponto de abolir a outra. Mas sua coexistência resulta, invariavelmente, não em um equilíbrio de simetria clássica, e sim em uma dinâmica de conflito.

Por isso os contos de temática local, cujas personagens são homens marginais, compadritos que intercalam cultura oral e cultura escrita, ou ainda oriundas da tradução feita de personagens alheias e canônicas como Fierro, Cruz e o Moreno, são emblemáticos na obra borgeana. Neles os pólos das relações dicotômicas que sempre sustentaram a defesa de uma identidade nacional fundem-se: a identidade encontra-se em constante migração entre o eu e o outro, possibilitando, assim, que se escute a voz das diferenças. Afinal, não somos um eu em oposição a um outro: somos o eu e o outro, nós e os outros, civilizados e bárbaros cujo pertencimento não pode ser delimitado. Em Biografia de Tadeo Isidoro Cruz e O Fim as personagens convertem-se em seres fronteiriços, assim como nos contos que se passam nos subúrbios, nos quais as personagens não podem ser definidas nem como gauchos, nem como homens urbanos, e cujo locus de enunciação também se faz fronteiriço (o arrabal: fronteira entre campo e cidade e, mais especificamente, a esquina e o armazém). Nessa fronteira, as histórias interpelam-se, cruzam-se e definem diferentes versões para o mesmo fato, diferentes identidades para um mesmo sujeito: lembremo-nos de que em um conto Rosendo Juárez é o covarde enquanto o narrador é o valentão que teve coragem de matar Francisco Real, ao passo que em outro o assassino é identificado como covarde por haver matado à traição, enquanto Rosendo é o homem de coragem por decidir largar aquela vida. Nestes contos, pois, Borges ouve e dá voz às muitas versões de 
um mesmo fato, às muitas faces de uma mesma identidade, eis que "o arrabal é muito contraste para que sua voz não mude nunca" (BORGES, 1994). Abolem-se, assim, as hierarquias e reconhece-se a hibridez que constitui qualquer sujeito e qualquer discurso. Assumindo seu papel de tradutor de histórias alheias, não interessa a Borges a verdadeira versão dos fatos, mas a possibilidade que estes fornecem para a construção de algo novo: sua narrativa, e por extensão, sua identidade de escritor latino-americano, também fronteiriço, híbrido e, por isso mesmo, incapaz da pretensão a uma identidade homogênea e a identificação de qualquer origem. Afinal, traduzir histórias, estabelecendo sobre elas diferentes leituras, é estabelecer, também, outra maneira de ler a si mesmo.

Assim, assumir a condição de fronteira, de entre-lugar ou de in-between é, não obstante, a posição mediadora ocupada frente a diferentes culturas. No entanto, faz-se importante salientar que a adoção desta posição não significa o abandono da consciência nacional. Esta não se confunde com o nacionalismo e é a única maneira de estabelecermos uma reflexão que alcance uma dimensão universal onde,

[...] o espaço-nação antinacionalista e ambivalente torne-se o cruzamento de caminhos para uma nova cultura transnacional. O 'outro' não está nunca fora ou mais além de nós; emerge necessariamente no discurso cultural, quando pensamos que falamos mais intimamente e autóctonamente 'entre nós' (BHABHA, 2000, p.216).

\section{REFERÊNCIAS BIBLIOGRÁFICAS}

BASSNETT, Susan. From Comparative Literature to Translation Studies. In: Comparative literature: a critical introduction. Oxford: Blacknell, 1993.

BHABHA, Homi K. Narrando la nación. In: BRAVO, Álvaro Fernández (org). La invención de la nación. Lecturas de la identidad de Herder a Homi Bhabha. Buenos Aires: Manantial, 2000. p.211-219.

BORGES, Jorge Luis. ___. Hombre de la esquina Rosada. In:___. Obras Completas de Jorge Luis Borges. Buenos Aires: Emecé, 1989. v. 1.

El idioma de los argentinos. Buenos Aires: Seix Barral / Biblioteca Breve, 1994.

El tamaño de mi esperanza. Buenos Aires: Seix Barral / Biblioteca Breve, 1995.

Historia de Rosendo Juárez. In: ___ _ El informe de Brodie. Buenos Aires: Editora Argentina, 2001-a.

Biografia de tadeo Isidoro Cruz. In: Obras Completas de Jorge Luis Borges. São Paulo: Globo, 2001-b. v. 1.

Discussão. In: Obras Completas de Jorge Luis Borges. São Paulo: Globo, 2001-c. v.1.

Evaristo Carriego. In:___ Obras Completas de Jorge Luis Borges. São Paulo: Globo, 2001-d. v.1.

. O Fim. In: _. Obras Completas de Jorge Luis Borges. São Paulo: Globo, 2001-e. v.1.

O Sul. In: __ Obras Completas de Jorge Luis Borges. São Paulo: Globo, 2001-f. v.1.

El "Martín Fierro". Buenos Aires: Editorial Columba, [s/d.].

BRAVO, Álvaro Fernández. Introducción. In:

Herder a Homi Bhabha. Buenos Aires: Manantial, 2000.

DERRIDA, Jacques. Lo Legible. In: ___ No escribo sin luz artificial. Valladolid, Espanha: Cuatro Ediciones, 1999, p.49-64.

HERNÁNDEZ, José. Martín Fierro. Buenos Aires: Editora Argentina, 2001.

KRISTEVA, Julia. Estrangeiros para nós mesmos. Tradução de Maria Carlota Carvalho Gomes. Rio de Janeiro: Racco, 1994.

MASSEY, Carlos Molina. Prólogo. In: HERNÁNDEZ, José. Martín Fierro. Buenos Aires: Ed. R. Müller, 1969. p 928.

MONEGAL, Emír Rodríguez. Borges por Borges. Tradução de Ernani Ssó. Porto Alegre: L\&PM, 1987.

PEDROSA, Célia. Nacionalismo Literário. In: JOBIM, José Luis (org). Palavras da Crítica. Rio de Janeiro: Imago, 1992. p.276-306.

PESAVENTO, Sandra Jatahy. Além das fronteiras. In: MARTINS, Maria Helena (org.). Fronteiras Culturais Brasil - Uruguay - Argentina. Cotia, SP: Ateliê Editorial, 2002. p. 35-39.

PAREKH, Bhikhu. El etnocentrismo del discurso nacionalista. In: BRAVO, Álvaro Fernández (org). La invención de la nación. Lecturas de la identidad de Herder a Homi Bhabha. Buenos Aires: Manantial, 2000. p.91122.

RIMSTEAD, Roxanne. Histórias orais como lócus de resistência. In: PETERSON, Michel; NEIS, Inácio A. (orgs.). As armas do texto: a literatura e a resistência da literatura. Porto Alegre: Editora Sagra Luzzatto, 2000. p.264-296.

SANTIAGO, Silviano (org). Glossário de Derrida. Rio de Janeiro: Francisco Alves, 1976.

. Apesar de Dependente, Universal. In: Vale quanto pesa. São Paulo: Perspectiva, 1978. p.13-24.

SARLO, Beatriz. Borges, um escritor en las orillas. Argentina: Espasa Calpe Argentina / Ariel, 1998.

SARMIENTO, Domingo Faustino. Facundo. 2.ed. Madrid: Cátedra, 1993. 
Conflicto y armonia de las razas en América. In: Obras Completas. Buenos Aires: Mariano Moreno, 1990.

SMITH, Anthony D. ¿ Gastronomia o geologia? El rol del nacionalismo en la reconstrucción. In: BRAVO, Álvaro Fernández (org). La invención de la nación. Lecturas de la identidad de Herder a Homi Bhabha. Buenos Aires: Manantial, 2000. p.185-209.

VÁZQUEZ, M. E. Borges: Imágenes, Memoria, Diálogos. Caracas: Monte Ávila, 1977.

VOLPE, Miriam. Geografias de exílio: Mario Benedetti. Montevideo: Ediciones La Gotera, [s/d.].

ZEA, Leopoldo. El proyecto de Sarmiento y su vigencia. In: Cuadernos Hispanoamericanos, 13. México: Universidad Nacional Autónoma de México, 1989.

Notas:

${ }^{\mathrm{i}}$ It is a plain with creeping vegetation.
ii It is a person who lives next to the frontiers among Brazil, Argentina or Uruguai (the Rio-Platense region). This typical term does not only mean
language, ethnics or region, properly. Gaúcho is more specific to convey the idea of a person who uses a primitive type of raising cattle for living.
iii Embora a palavra "pampa" seja de gênero masculino em português, opto por utilizá-la no gênero feminino, conforme o espanhol (la pampa). 